\title{
QUÍMICA É UMA CIÊNCIA EM EXPANSÃO
}

Dois fatos importantes relacionados ao anúncio dos ganhadores do Prêmio Nobel de Química de 2009 merecem uma leitura mais detalhada. O Prêmio Nobel foi concedido a três cientistas (Venkatraman Ramakrishnan, Thomas Steitz e Ada Yonath) pelos seus estudos em biologia molecular relacionados com a função e a estrutura dos ribossomos. A Profa. Ada Yonath, do Instituto Weizmann de Israel, foi a quarta mulher a receber o Nobel de Química, pois procurou entender em nível atômico o funcionamento dos ribossomos por cristalografia de raios X. Há mais de quatro décadas uma mulher não recebia esta premiação; as ganhadoras do Nobel de Química foram Marie S. Curie - 1911; Irène Joliot-Curie - 1935 e Dorothy C. Hodgkin - 1964.

Em nosso editorial do No. 2 deste ano, destacamos que a 63ª Assembléia Geral das Nações Unidas (ONU) elegeu 2011 como o Ano Internacional da Química, em homenagem ao centenário do primeiro Prêmio Nobel em Química, conferido à Marie S. Curie em "reconhecimento das contribuições das mulheres para a Ciência e da Química para o bem-estar da humanidade". 1

Mais interessante ainda foi saber que a premiação de 2009 bateu o recorde em termos de mulheres ganhadoras do prêmio. Isso demonstra claramente que a ciência está deixando de ser um lugar exclusivo dos homens, pois as mulheres contribuíram e contribuem muito para o seu avanço. Ainda há muito a avançar, pois até o momento em que escrevemos este editorial apenas 36 mulheres $(4,4 \%)$ foram agraciadas com o prêmio, e isso de forma alguma representa o universo das mulheres na ciência.

Outro ângulo interessante a ser analisado na premiação de 2009 em Química é a interface Química-Biologia, também conhecida como biologia molecular, na qual os pesquisadores desenvolveram seus importantes trabalhos.

Dentro das ciências, a Química é conhecida como uma ciência central, porém já há algum tempo as premiações do Nobel têm sido direcionadas para suas interfaces mais próximas (física, biologia, farmácia, ecologia, geologia, nanotecnologia, nanomedicina, nutrição etc). A centralidade da Química foi recentemente tema de editorial do Journal of the Brazilian Chemical Society, destacando que para o público a Química parece ser uma ciência envelhecida, mas na realidade ela alimenta constantemente suas interfaces com a ampliação dos conceitos químicos, elevando o entendimento dos fenômenos ao nível molecular e atômico. ${ }^{2}$ Se por este ângulo podemos considerar isso como um ponto positivo, também é um ponto negativo, pois frequentemente suas realizações não são reconhecidas pela sociedade, que vê a Química com um olhar negativo e, em alguns casos, até mesmo de reprovação.

A Química é solução e não problema. É uma ciência prática, que impacta extremamente a vida humana. Ela é a chave para o entendimento do nosso mundo e de seu funcionamento. De vasta aplicação, fornece materiais e métodos para outras ciências e tecnologias. Em realidade, a Química se encontra nas temáticas mais importantes para a sociedade, que vão desde a melhoria da qualidade da saúde, aumento da expectativa de vida, utilização racional e conservação dos recursos naturais, proteção do meio ambiente, toda a cadeia de produção e conservação dos alimentos (segurança alimentar), materiais do dia-a-dia, farmoquímicos, medicamentos, cosméticos, construções, qualidade da água, produtos de higiene, petroquímicos, combustíveis limpos etc, ou seja, a Química está em tudo que utilizamos diariamente.

Infelizmente, alguns processos químicos e produtos também têm o potencial de prejudicar a nossa saúde ou o meio ambiente. Estes devem ser banidos e/ou substituídos por outros mais seguros. A Química também tem sido a solução para estes casos. Se alguns produtos perigosos não foram substituídos imediatamente, a única razão foi a ganância de alguns visando o lucro desmedido. Já afirmamos anteriormente que "O lucro de alguns com degradação ambiental é prejuízo de todos". ${ }^{1} \mathrm{~A}$ educação dos cidadãos consumidores sobre a importância da Química tem que ser permanente para melhorar a sua imagem e ampliar o conhecimento de como os produtos químicos influenciam suas vidas, encontrando um equilíbrio sobre seus usos adequados.

Alguns podem pensar que o futuro da Química é incerto, ou até que ela não tem futuro. Porém, a realidade mostrará que a ciência Química encontrará soluções para diversos desafios como a otimização e descobrimento de novas reações químicas, o entendimento de como o mundo nos níveis atômico e molecular se relaciona com o mundo macroscópico no qual vivemos, as estruturas tridimensionais e as ligações nas moléculas e supramoléculas ao nível celular, as formas dinâmicas nas quais os químicos são capazes de controlar as propriedades da matéria, os processo de auto-organização, o desenvolvimento de moléculas mágicas que podem atingir doenças seletivamente, dentre muitos outros que surgirão ao longo do seu desenvolvimento.

Ao contrário de outras ciências, a Química é um universo em expansão. Não é ufanismo destes editores. Se observarmos atentamente, o Prêmio Nobel de Medicina foi concedido a três cientistas americanos que descobriram uma enzima que ajuda o cromossomo a proteger o código genético. Suas pesquisas ajudarão a entender o envelhecimento, a gênese dos cânceres e o comportamento das células tronco. Se fosse conferido pela Química, não seria nada surpreendente, pois Química é uma ciência central.

Susana I. Córdoba de Torresi Vera L. Pardini Vitor F. Ferreira Editores de QN

\section{REFERÊNCIAS}

1. Torresi, S. I. C.; Pardini, V. L.; Ferreira, V. F.; Quim. Nova 2009, 32, 275.

2. Bursten, B. E.; J. Braz. Chem. Soc. 2009, 20 (7), iii. 